\title{
Youth in transition: Study protocol of a prospective cohort study into the long- term course of addiction, mental health problems and social functioning in youth entering addiction treatment
}

\author{
Christina Moska ${ }^{1,2}$, Anna E. Goudriaan ${ }^{3,4^{*}}$ (D), Peter Blanken ${ }^{1}$, Dike van de Mheen ${ }^{5}$, Renske Spijkerman ${ }^{1}$,
} Arnt Schellekens ${ }^{6,7}$, Jannet de Jonge ${ }^{8}$, Floris Bary ${ }^{9}$, Wilma Vollebergh ${ }^{10}$ and Vincent Hendriks ${ }^{1,2}$

\begin{abstract}
Background: Substance use disorders (SUDs) are prevalent in the general population, tend to follow a chronic course, are associated with many individual and social problems, and often have their onset in adolescence. However, the knowledge base from prospective population surveys and treatment-outcome studies on the course of SUD in adolescents is limited at best. The present study aims to fill this gap and focuses on a subgroup that is particularly at risk for chronicity: adolescents in addiction treatment. We will investigate the rate of persistent SUD and its predictors longitudinally from adolescence to young adulthood among youth with DSM-5 SUD from the start of their addiction treatment to 2 and 4 years following treatment-entry. In addition to SUD, we will investigate the course of comorbid mental disorders, social functioning, and quality of life and their association with SUD over time.

Methods/design: In a naturalistic, multi-center prospective cohort design, we will include youths $(n=420)$, who consecutively enter addiction treatment at ten participating organizations in the Netherlands. Inclusion is prestratified by treatment organization, to ensure a nationally representative sample. Eligible youths are 16 to 22 years old and seek help for a primary DSM-5 cannabis, alcohol, cocaine or amphetamine use disorder. Assessments focus on lifetime and current substance use and SUD, non-SUD mental disorders, family history, life events, social functioning, treatment history, quality of life, chronic stress indicators (hair cortisol) and neuropsychological tests (computerized executive function tasks) and are conducted at baseline, end of treatment, and 2 and 4 years postbaseline. Baseline data and treatment data (type, intensity, duration) will be used to predict outcome - persistence of or desistance from SUD.
\end{abstract}

\footnotetext{
* Correspondence: a.e.goudriaan@amsterdamumc.nl

${ }^{3}$ Department of Psychiatry, Academic Medical Centre, University of Amsterdam, Amsterdam, the Netherlands

${ }^{4}$ Amsterdam Institute for Addiction Research, Arkin Mental Health Care, Amsterdam, the Netherlands

Full list of author information is available at the end of the article
}

(c) The Author(s). 2021 Open Access This article is licensed under a Creative Commons Attribution 4.0 International License, which permits use, sharing, adaptation, distribution and reproduction in any medium or format, as long as you give appropriate credit to the original author(s) and the source, provide a link to the Creative Commons licence, and indicate if changes were made. The images or other third party material in this article are included in the article's Creative Commons licence, unless indicated otherwise in a credit line to the material. If material is not included in the article's Creative Commons licence and your intended use is not permitted by statutory regulation or exceeds the permitted use, you will need to obtain permission directly from the copyright holder. To view a copy of this licence, visit http://creativecommons.org/licenses/by/4.0/ The Creative Commons Public Domain Dedication waiver (http://creativecommons.org/publicdomain/zero/1.0/) applies to the data made available in this article, unless otherwise stated in a credit line to the data. 
Discussion: There are remarkably few prospective studies worldwide that investigated the course of SUD in adolescents in addiction treatment for longer than 1 year. We are confident that the Youth in Transition study will further our understanding of determinants and consequences of persistent SUD among high-risk adolescents during the critical transition from adolescence to young adulthood.

Trial registration: The Netherlands National Trial Register Trial NL7928. Date of registration January 17, 2019.

Keywords: Adolescents, Youth addiction treatment, Substance use disorder, Long-term course of SUD, Prospective cohort study

\section{Background}

Substance use disorders (SUDs) are prevalent in the general adult population [1], tend to follow a chronic or chronic-intermittent course, are associated with many individual and social problems, and - as most mental disorders - often have their onset in adolescence [2]. Hence, the course of SUD among adolescents and young adults should be high on our research agenda. Nevertheless, the literature regarding the development, persistence or desistance and treatment of SUD in youth is sparse, and research in this area lags considerably behind that of research in adult SUD.

When studying substance use 'trajectories' several transitions can be distinguished. The first series of transitions cover the initiation of substance use, and the transition from first use to regular or frequent use, and from frequent use to disordered use. The subsequent transition pertains to the persistence or desistance of SUD. In the present study we examine the last transition - the persistence of or desistance from SUD in the period from late adolescence (i.e., 16 to $22 \mathrm{yrs}$ ) to early adulthood (20 to 26 yrs) - among youth in addiction treatment.

Various prospective studies have traced the progression from first substance use through frequent consumption to the onset of SUD in community samples of adolescents, with most studies pertaining to cannabis, the most commonly used illicit drug worldwide [3-7]. Most substance use in adolescents remains experimental, irregular or modest. However, it tends to become more frequent, intensive and long-lasting when the use of substances is part of multiple problem behavior including comorbidity with mental health problems, social dysfunction, and delinquency [7-9].

Much less is known about what happens next: the course of SUD during the critical transition period from adolescence to adulthood. Based on Moffitt's taxonomy of antisocial behavior [10, 11], the literature distinguishes between adolescent-limited and life-coursepersistent trajectories of substance use and SUD, but few prospective population studies have in fact addressed this issue, and virtually all studies were conducted in the
United States, Australia and New Zealand [12-16]. For example, Meier et al. (2015) investigated the development of persistent substance dependence on alcohol, nicotine, cannabis or hard drugs from adolescence to adulthood up to 38 years in the Dunedin birth cohort in New Zealand, and found a persistence rate of substance dependence of $19 \%$ when including nicotine dependence, and of $9 \%$ when excluding nicotine dependence from the outcome. In addition, they found a specific set of childhood and adolescent risk factors, including family history of SUD, childhood psychopathology, and childhood socioeconomic status, to be strongly associated with persistent substance dependence in adulthood. Only a few European population studies investigated the course of SUD from adolescence to young adulthood, but these focused on cannabis only $[17,18]$.

The present study focuses on a population that is particularly at risk for chronicity: adolescents in addiction treatment. Although research on treatment outcome of adolescents with SUD has expanded in the past decade [19], there are remarkably few studies that investigated the course of SUD in adolescents following addiction treatment prospectively for longer than 1 year. We found only three large-scale $(N>300)$ studies that did so [20-22]. Results from these - all US-based - studies suggest that, despite overall treatment benefit, roughly 15 to $30 \%$ of treated adolescents show a pattern of persistent SUD/dependence or even deterioration during the 3 to 6 years post-treatment.

To conclude, the available data from prospective population surveys and treatment-outcome studies on the course of SUD in adolescents are limited at best. Remission, continuation and progression rates are largely unknown, as are the risk and protective factors involved. While nearly 6000 youth aged 22 years or younger enter treatment for SUD annually in the Netherlands [23], we have virtually no information as to how these youth will fare moving from adolescence to early adulthood. The present study aims to fill these gaps by addressing the study objectives outlined below. 


\section{Study objectives}

In this study, we will investigate the rate of persistent SUD and its predictors longitudinally from adolescence to young adulthood in a representative treatment sample of youth with DSM-5 SUD from the start of their addiction treatment to 2 and 4 years following treatmententry. In addition to SUD, we will investigate the course of comorbid mental disorders and social functioning, and their relation with SUD over time.

Our primary study questions are:

(1) What is the persistence rate of DSM-5 moderate to severe SUD from adolescence to young adulthood among youth in the two and four years following entry in addiction treatment?

(2) What is the prognostic value of a general population-based set of predictors of persistent SUD - based on the Dutch Tracking Adolescents' Individual Lives Survey (TRAILS) study - from adolescence to young adulthood for predicting persistent DSM-5 moderate to severe SUD among youth in addiction treatment?

(3) Can we optimize the accuracy of predicting persistent DSM-5 moderate to severe SUD among youth in addiction treatment by extending or modifying the general population-based set of predictors with baseline indicators from our addiction treatment sample?

(4) Which longitudinal treatment outcome trajectories can be identified from adolescence to young adulthood pertaining to substance use and SUD, comorbid mental health problems, and social functioning among youth in addiction treatment?

(5) Which treatment interventions - in terms of type, intensity and duration - are associated with favorable or unfavorable long-term outcomes, in terms of substance use and SUD, mental health problems and social functioning, for which youth in addiction treatment?

\section{Methods}

\section{Research design}

Our study is designed as a naturalistic, multi-center prospective cohort study among youth seeking help in addiction treatment to investigate the study objectives mentioned above.

We will recruit youth aged 16 to 22 years $(N=420)$ who enter addiction treatment at ten participating treatment organizations from a total of 13 organizations in the Netherlands. Participants will be assessed on a range of measures related to substance use and SUD, comorbid mental health problems and social functioning at treatment-entry (baseline), end of treatment, and 2 and 4 years post-baseline. Study-inflow of participants consists of consecutive admissions, and will be prestratified by treatment organization to ensure a nationally representative sample. Treatment consists of treatment as usual, as provided by the participating addiction care organizations, to maximize generalizability of the study findings to everyday clinical practice. Analyses will be conducted following an intention-to-treat approach.

This study was funded by The Netherlands Organization for Health Research and Development (60-63,600-98-317) and was approved by the Medical Ethical Board of the Leiden University Medical Center (NL65903.058.18; file number P18.175). Trial registration: NL7928.

\section{Participants and setting}

Based on national treatment registration data [23], a total of 5769 youth up to age 22 years applied for addiction treatment in the Netherlands in 2015. From these, the far majority $(N=5151 ; 89 \%)$ were 16 to 22 years old, and most sought help for a primary cannabis- (53\%), alcohol- $(17 \%)$ or stimulant- $(11 \%$, cocaine or amphetamine) related problem. Hence, $81 \%(N=4169)$ of total treatment demand among youth aged 16-22 years concerns cannabis, alcohol, cocaine and/or amphetamines, with other substances (e.g., opiates, ecstasy, GHB, and benzodiazepines) each representing less than $2 \%$ of treatment demand. Limiting our inclusion to youth aged 16-22 years, with the primary substances mentioned above, and using a sampling fraction of $10 \%, 420$ youth will be included in our study (see Fig. 1).

Inclusion criteria are: age 16 to 22 years; primary SUD pertains to cannabis, alcohol, cocaine or amphetamines; willingness to participate in the study (oral and written informed consent). Exclusion criteria are: referral for diagnostic evaluation only; insufficient comprehension of basic Dutch language. The ten participating organizations include specialized addiction treatments and integrated mental health and addiction treatments, with treatment covered by the health insurance system. Recruitment of study participants takes place at 41 treatment locations situated throughout the Netherlands.

\section{Treatment}

Treatment consists of the usual treatment-offer provided by the addiction care organizations to maximize ecological validity of the study outcomes. We will document the type of treatment received for SUD, which in the Netherlands mostly consists of integrated cognitive behavioral therapy plus motivational interviewing (CBT + $\mathrm{MI})$, community reinforcement approach (CRA), family therapy, and CBT-based e-health interventions. In addition, we will document - psychosocial and/or pharmacological - treatment for comorbid mental health problems as well as intensity (inpatient; 


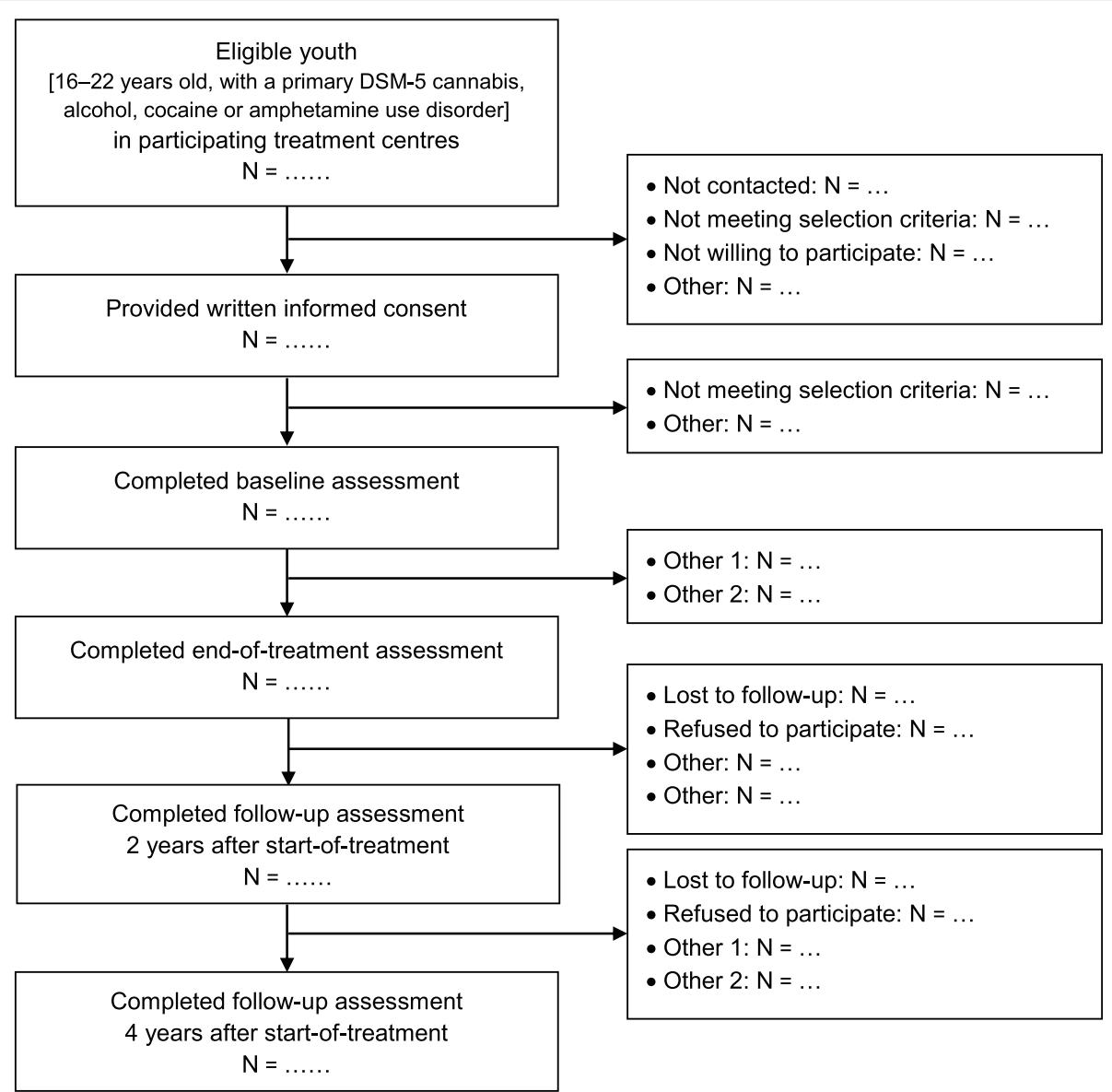

Fig. 1 Flowchart of the Youth in Transition study

outpatient) and actual duration (retention) of treatment, and type of treatment termination (premature/planned).

\section{Assessments}

Study assessments take place at study-entry (baseline), end of treatment, and 2 and 4 years post-baseline, and will be conducted by trained, academic level, research assistants, who are independent from the treatmentstaff. Youth who apply for treatment at the participating treatment centers will be approached by treatment-staff with the request to participate in the study. Following screening for eligibility, participants are asked to provide informed consent, after which the baseline assessment and subsequent two- and four-years follow-up will be conducted.

For the purpose of the present study, we developed the Youth in Transition Questionnaire (YIT-Q [24]), which contains both widely used instruments like the Depression, Anxiety and Stress Scale (DASS-21 [25]) and the World Health Organization Disability Assessment Schedule (WHODAS-2.0 [26]) as well as domains with item-sets that were developed by our research group (see Table 1). Both the DASS-21 and the WHODAS-2.0 have shown a stable factor structure, and their scales have excellent internal consistency reliability and good convergent en discriminant validity (e.g., [27, 28]).

At baseline, we collect sociodemographic information and administer the substance use section of the Measurements in the Addictions for Triage and Evaluation Youth version (MATE-Y [29]), which is the standard intake instrument in most youth addiction treatment organizations in the Netherlands. Both lifetime (onset, duration) and past-month (days of use) substance use data are collected, and the criteria of the fifth edition of the Diagnostic and Statistical Manual of Mental Disorders (DSM-5 [30]) are administered to obtain a lifetime and past-year diagnosis of SUD for the primary and - if present - secondary substance for which the youths seek help. To assess the presence of comorbid non-SUD mental disorders, we developed a structured DSM-5 diagnostic interview which covers ten of the most common disorders: depression; panic disorder; agoraphobia; social phobia; post-traumatic stress disorder; attention- 
Table 1 Assessment domains and instruments

\begin{tabular}{|c|c|c|c|c|c|}
\hline & Instrument & Baseline & $\begin{array}{l}\text { End of } \\
\text { treatment }\end{array}$ & $\begin{array}{l}2 \text { year } \\
\text { FU }\end{array}$ & $\begin{array}{l}4 \text { year } \\
\text { FU }\end{array}$ \\
\hline \multicolumn{6}{|l|}{ Demographic background } \\
\hline - Age; sex; cultural background/identity & YIT-Q & $x$ & & & \\
\hline - Family educational level and socioeconomic status & YIT-Q & $x$ & & & \\
\hline \multicolumn{6}{|l|}{ Substance use } \\
\hline - Lifetime and recent substance use & MATE-Y & $x$ & & $x$ & $x$ \\
\hline - DSM-5 substance use disorder (SUD); age of onset & MATE-Y & $x$ & & $x$ & $x$ \\
\hline \multicolumn{6}{|l|}{ Non-SUD mental disorders } \\
\hline - DSM-5 lifetime and past-year mental disorders; age of onset & Structured DSM-5 interview & $x$ & & $x$ & $x$ \\
\hline \multirow{2}{*}{$\begin{array}{l}\text { - Dimensional measures of mental health problems, including } \\
\text { depression, anxiety, stress; prodromal psychotic symptoms; } \\
\text { personality risk for substance abuse; intellectual disability }\end{array}$} & DASS-21; PQ-16; & $x$ & & $x$ & $x$ \\
\hline & SURPS; SCIL & $x$ & & & \\
\hline - Suicidal ideation/attempts & $\mathrm{MINI}$ & & & $x$ & $x$ \\
\hline \multicolumn{6}{|l|}{ Family history/environment } \\
\hline - History of SUD (parents; grandparents; siblings) & YIT-Q & $x$ & & & \\
\hline \multirow{2}{*}{$\begin{array}{l}\text { • History of non-SUD mental disorders; criminality, } \\
\text { violence, abuse, neglect, homelessness }\end{array}$} & YIT-Q & $x$ & & & \\
\hline & YIT-Q & $X$ & & & \\
\hline \multicolumn{6}{|l|}{ Life events } \\
\hline - Traumatic life events & Structured DSM-5 interview & $x$ & & $x$ & $x$ \\
\hline - Turning points with major impact on addiction course & YIT-Q & & & $x$ & $x$ \\
\hline \multicolumn{6}{|l|}{ Social functioning } \\
\hline $\begin{array}{l}\text { - Youth's functioning in the areas of: education; employment; } \\
\text { living arrangements; social relationships/support; delinquency }\end{array}$ & YIT-Q & $x$ & & $x$ & $x$ \\
\hline - General functioning, disability and quality of life & WHODAS-2.0 & $x$ & & $x$ & $x$ \\
\hline \multicolumn{6}{|l|}{ Treatment history } \\
\hline $\begin{array}{l}\text { - Number/types of earlier addiction and mental health } \\
\text { treatments }\end{array}$ & YIT-Q & $x$ & & $x$ & $x$ \\
\hline - Intention/motivation for current treatment & YIT-Q & $x$ & & & \\
\hline \multicolumn{6}{|l|}{ Endophenotype and biomarker } \\
\hline - Behavioral measures of impulsivity (computerized tasks) & $\begin{array}{l}\text { Risky Gains task, VBDM, Self- } \\
\text { Ordered Pointing task }\end{array}$ & $x$ & & $x$ & $x$ \\
\hline - Biomarkers of chronic stress: hair cortisol and testosterone & Hair sample analysis & $x$ & & $x$ & $x$ \\
\hline \multicolumn{6}{|l|}{ Index treatment characteristics } \\
\hline $\begin{array}{l}\text { - Type, intensity, duration of current treatment received and initial } \\
\text { treatment response }\end{array}$ & & & $x$ & & \\
\hline
\end{tabular}

deficit/hyperactivity disorder; conduct disorder; anorexia nervosa and bulimia nervosa; generalized anxiety disorder. For each disorder, the main diagnostic criteria are used as screening questions, and only if these main criteria are met in a period that the person was not intoxicated and did not experience alcohol or drug withdrawal symptoms - hence, do not reflect a substance-induced disorder only - the full section of that disorder is administered. In addition to DSM-5 classification, the DASS-21 (depression, anxiety, stress), Prodromal Questionnaire (PQ-16 [31]) (subclinical psychotic symptoms), Substance Use Risk Profile Scale (SURPS [32]) (personality risk for substance abuse) and Screener for Intelligence and Learning disability (SCIL [33]) are administered to obtain dimensional measures of mental health, and the WHODAS-2.0 is used to assess general 
functioning, disability and quality of life. The PQ-16 was found to accurately identify ultra high risk (UHR) and full psychosis, with area under the curve (AUC) values ranging from 0.71 to 0.95 [34], and the SURPS showed adequate to high internal consistency (Cronbach's alpha $=0.61-0.86$ ), a stable factor structure that reflects the four scales of the instrument, and good test-retest reliability, with intra-class correlation coefficients (ICC) ranging from 0.68 to 0.88 [35]. The SCIL has shown excellent test-retest reliability (Pearson's $r=0.92$ ) and good predictive validity for detecting mild or borderline intellectual disabilities in both adults $(\mathrm{AUC}=0.93)$ and youths $(\mathrm{AUC}=0.91)$ [33].

The YIT-Q assessment domains pertaining to family history/environment, social functioning and treatment history/motivation all contain structured questions which inform about the youth's self-reported perception of his/her own functioning or problems in these areas, or - in the case of family history - his/her perception of his family members' functioning/problems (see Table 1). Questions pertaining to suicidal ideation/attempts were derived from the Mini International Neuropsychiatric Interview (MINI, version 5.0.0 [36]). For assessing family history of SUD, non-SUD mental disorders and criminality we used the Family History Method (FHM [37]) as described by Schuckit et al. (2020). Given that the FHM tends to underestimate family diagnosis, we aimed to increase its sensitivity by asking the youth whether his/her (grand)parent(s) or sibling(s) had ever received treatment for alcohol, drug or mental health problems, or whether they had ever been incarcerated. We derived and adapted a set of questions about family history of violence, abuse and neglect towards the youth from the International Society for the Prevention of Child Abuse \& Neglect (ISPCAN) Child Abuse Screening Tools (ICAST), version for young adults (ICAST-R [38]). For assessing important 'turning points' that had a major impact on the course of the youth's substance use career, we will use a qualitative approach with open-ended questions [39]. Questions on the youth's social functioning, including employment, living arrangements, social support and delinquency were derived and adapted from item-sets in the Substance Use Recovery Evaluator (SURE [40]) and the Treatment Outcomes Profile (TOP [41]). Both instruments are widely used and validated, and are included in the recent International Consortium for Health Outcomes Measurement (ICHOM [42]) standard set for addiction. For example, the five subscales of the SURE showed good internal consistency (alpha $=0.68-0.87)$, and reflect a stable factor structure of the instrument [40]. In addition, all items of the TOP in the areas of employment, living arrangements and delinquency showed 'substantial' or 'good' inter-rater reliability, with Cohen's kappa $>0.61$, and ICC $>0.75$, respectively [41]. We limited our assessment of intention/motivation for treatment to a single-item question pertaining to the youth's self-reported primary goal of treatment - total abstinence or strong/small/no reduction of substance use.

In addition to the self-reported measures described above, we administer several computerized tasks pertaining to impulsive or risky choice and value-based decision-making (VBDM). Specifically, we include a delay discounting task, in which four versions are administered: a) delay discounting; b) probability discounting of gains; c) probability discounting of losses; d) mixed gambles. The task is administered using MATLAB software; further details on task description can be found in [43]. In addition, a computerized selfordered pointing task is administered using Inquisit software, based on Petrides and Milner (1982) from the Inquisit test library [44]. Lastly, we administer an Inquisit version of the Risky Gains Task developed by Paulus et al. (2003) $[45,46]$. Concerning discounting in adolescents, studies have shown that individual differences in decision-making are stable over time, as indicatated by moderate to good test-retest reliability even over a 2year interval, with ICC-values ranging from 0.65 to 0.78 [47]. Lastly, we collect a scalp hair sample of (if possible) at least $3 \mathrm{~cm}$ and analyze hair cortisol and testosterone to obtain a biological measure of chronic stress. Hair cortisol analysis is increasingly used in mental health research, and is a reliable method to determine cortisol levels over a prolonged period of time [48, 49]. In addition, it has recently been shown that psychosocial stress increases testosterone levels in both healthy controls and patients with posttraumatic stress-disorder and borderline personality disorder [50]. We therefore also assess hair testosterone levels, in order to have an additional read-out for physiological effects of chronic stress and explore a potential link between elevated testosterone and impulse regulation issues among youth with substance use disorders.

The end-of-treatment assessment will be limited to documenting the judgement of the youth's primary clinician about the youth's short-term treatment response (partial or full remission; persistence; deterioration of problematic substance use) and documenting the treatment received (type; intensity; duration) and type of treatment termination (premature; planned).

With the exception of most demographic background variables and questions pertaining to pre-baseline history, the two- and four-year follow-up interviews will focus on the same domains and include the same instruments as the baseline assessment, with time-frames adapted to the follow-up period. In addition, we will inquire whether the youth experienced important 'turning points' or major life events that, in his or her view, 
had a major impact on the course of his/her substance use in two- and four-years follow-up period.

Time to administer the baseline and follow-up assessments is estimated at 2 and $1.5 \mathrm{~h}$ each, respectively. The assessments will preferably be conducted at the treatment center. Youth will receive a remuneration of 20, 30 and 50 euro for participating in the baseline and twoand four-year follow-up, respectively. In addition, they have the possibility to win a gift certificate of 200 euro ( 6 certificates available) for follow-up attendance, as has been done successfully in previous studies [51].

\section{Power considerations}

Using a sampling fraction of $10 \%$ to obtain a representative sample from the total target population $(N=4169$; see 'Participants and setting' above), we aim to include 420 youth in our study. Concerning our first study question, we assume a $30 \%$ persistence rate of moderate to severe SUD in our study sample [20, 21, 52]. With precision at 5\% [53], a minimum sample size of $N=300$ would be sufficient to estimate the assumed $30 \%$ persistence rate with a 95\% level of confidence [54].

However, for our prediction analyses of persistent SUD (study questions 2, 3 and 5) we need a larger sample size than $\mathrm{N}=300$ to allow a sufficiently large number of predictor variables to be included in the logistic regression models. To avoid overfit of a logistic regression model, authors recommend a minimum of 10 events (i.e., 10 patients with persistent SUD) for each predictor variable [55-57]. Hence, given the assumed $30 \%$ persistence rate, and $N=420$, a maximum of 12 predictor variables could be included in the multivariate logistic regression analysis.

\section{Data analysis}

Study data will be analyzed following an intent-to-treat (ITT) approach. The ITT-population consists of all patients who provide informed consent and receive at least one treatment session.

(1) What is the persistence rate of DSM-5 moderate to severe SUD from adolescence to young adulthood among youth in the 2 and 4 years following entry in addiction treatment?

Persistent moderate to severe SUD is defined as meeting the criteria of lifetime moderate to severe SUD for alcohol, cannabis, cocaine or amphetamines - collapsed across substances - at baseline, as well as meeting the criteria of past-year moderate to severe SUD at both the 2 year and 4 year follow-up. According to DSM-5, moderate to severe SUD is defined as meeting four or more of the 11 SUD-criteria. In case of missing follow-up data we will conduct sensitivity analyses, using multiple imputation methods based on post-baseline treatment, end-of-treatment and follow-up data that we do have available of a participant. We will also conduct a 'worstcase' scenario analysis, in which those not reached at both the two- and four-year follow-up are considered as youth with persistent SUD. Notably, for youth without past-year SUD at the 2 year follow-up and a missing 4 year follow-up (and vice versa), our primary outcome variable is available: they are - by definition - youth with non-persistent SUD.

(2) What is the prognostic value of a general population-based set of predictors of persistent SUD from adolescence to young adulthood for predicting persistent DSM-5 moderate to severe SUD among youth in addiction treatment?

We will use existing data from the Tracking Adolescents' Individual Lives Survey (TRAILS) study to investigate the rate of persistent substance dependence (DSMIV) and its predictors from adolescence to young adulthood in the general population. TRAILS is a prospective cohort study $(N=2230)$ into the development of mental health from preadolescence (age 11 years) to adulthood (up to age 26 years) in the Dutch general population with five biennial or triennial follow-up waves [58]. Candidate-predictors stem from the areas of: demographic background; substance use and SUD; non-SUD mental disorders; family history; life events; and social functioning (see first six domains in Table 1). Logistic regression will be used to investigate the relation of these predictors with the outcome variable, persistent substance dependence, following the two-step procedure suggested by Hosmer and Lemeshow (2000) [59]. Only variables which are significantly associated with the outcome variable in the first, univariate, step will be entered as candidates into the multivariate (backward) logistic regression model in the second step. Next, we will evaluate the accuracy of the set of combined adolescent risk factors found to predict persistent substance dependence in the TRAILS cohort for predicting persistent DSM-5 moderate to severe SUD among youth in addiction treatment, in terms of sensitivity, specificity, and positive and negative predictive value.

(3) Can we optimize the accuracy of predicting persistent DSM-5 moderate to severe SUD among youth in addiction treatment by extending or modifying the general population-based set of predictors with baseline indicators from our addiction treatment sample?

This question will be addressed (a) by building a new prediction model based upon the same potential 
predictor variables as used in the TRAILS analysis above, and supplement these with potential predictor variables assessed at baseline in our addiction treatment sample (Table 1), and (b) by comparing the accuracy of this treatment-based prediction model with the TRAILSpopulation-based prediction model.

(4) Which longitudinal treatment outcome trajectories can be identified from adolescence to young adulthood pertaining to substance use and SUD, comorbid mental health problems, and social functioning among youth in addiction treatment?

Concerning the fourth study question, we will use the total count of DSM-5 SUD-symptoms derived from the MATE-Y, and the sum score on the DASS-21 (mental health problems) and WHODAS 2.0 (social functioning), assessed at baseline and at two- and four-years followup (Table 1). To describe the longitudinal course of SUD, mental health problems and social functioning we will employ latent growth curve modeling [60].

(5) Which treatment interventions - in terms of type, intensity and duration - are associated with favorable or unfavorable long-term outcomes, in terms of substance use and SUD, mental health problems and social functioning, for which youth in addiction treatment?

The fifth study question will be answered in two successive steps. First, we will determine which treatment interventions are associated with a favorable treatment outcome, using the same two-step logistic regression procedure as described for study question 3. Next, we will determine whether the youth-related potential predictors for persistent SUD (see study question 3) moderate the favorable or unfavorable long-term outcomes of the different treatment interventions. To determine which treatment interventions are associated with a favorable long-term - two- and four-years - outcome, we will categorize the treatment received along the following dimensions: type of treatment; intensity; duration; type of termination (see section 'Treatment' above).

All study questions will be analyzed using the statistical software packages of SPSS version 25, R, and Mplus, where appropriate.

\section{Discussion}

This study aims to investigate the long-term course of SUD, concurrent mental health problems and social functioning in a group that is particularly at risk for chronicity: youth in addiction treatment. Strengths of the study are (1) obtaining a nationally representative sample of youth in addiction treatment, (2) the relatively large size of our cohort, (3) the use of both self-report and endophenotypical biological and cognitivebehavioral data, and (4) our aim to determine the longterm outcome of youth addiction treatment in a naturalistic, 'real world' treatment context. Study limitations include the following. First, our study sample consists of youth aged 16 to 22 years. We would have preferred to include younger adolescents as well, but Dutch national registration data showed that only 618 youths aged 15 years and younger seek help at addiction treatment annually (i.e., $11 \%$ of total youths' treatment demand). Second, our maximum follow-up period is 4 years. We would have preferred a longer follow-up period (e.g., 8 to 10 years) to sufficiently cover the age of young adulthood, but this was not possible due to budget limitations. Third, our study data are in essence correlational in nature, and hence, are subject to confounding. Including a non-treatment control group would limit confounding, but for reasons of feasibility, ethics and costs, we chose not to include a non-treatment (matched) control cohort in our study. Another option would have been to conduct a large-scale randomized controlled trial (RCT), but for obvious reasons an RCT with a nontreatment control group would be unacceptable for ethical reasons. Nevertheless, we will include important and well-known confounders like social economic status in our analyses. Lastly, most of our data are based on selfreport and may be subject to underreporting. Selfreported substance use can be verified by means of urinalyses, but this method only provides a momentary assessment and does not give an indication of amount or severity of use. Studies indicate that self-report is quite reliable if confidentiality is guaranteed and if no negative consequences are attached to the answers provided by the person $[61,62]$. To assure that this will be the case, our study assessments will be conducted by researchassistants that are independent from treatment-staff. Nevertheless, youths with insufficient comprehension of basic Dutch language will be barred from the study (exclusion criterion), and hence this potentially important subpopulation will not be represented in our study data.

All in all, we are confident that this study will further our understanding of (1) the course of SUD in youths seeking help for their addiction problems, (2) the relationship between SUD and comorbid mental disorders and social functioning over time, and (3) the determinants and consequences of persistent SUD during the transition from adolescence to young adulthood.

\footnotetext{
Abbreviations

CBT: Cognitive behavioral therapy; CRA: Community reinforcement approach; DASS-21: Depression, anxiety and stress scale; DSM-IV: Diagnostic and statistical manual of mental disorders, fourth edition; DSM-5: Diagnostic and statistical manual of mental disorders, fifth edition; ITT: Intent-to-treat; MATEY: Measurements in the addictions for triage and evaluation - youth version; MI: Motivational interviewing; PQ-16: Prodromal questionnaire;
} 
RCT: Randomized controlled trial; SCIL: Screener for intelligence; SPSS: Statistical package for the social sciences; SUD: Substance use disorder; SURPS: Substance use risk profile scale; TRAILS: Tracking adolescents' individual lives survey; YIT: Youth in transition; YIT-Q: Youth in transition questionnaire; WHODAS-2.0: World health organization disability assessment schedule.

\section{Acknowledgements}

This study is a collaboration between Parnassia Addiction Research Centre (PARC), Academic Medical Centre (AMC) University of Amsterdam, Nijmegen Institute for Science Practitioners in Addiction (NISPA) and department of Tranzo Scientific Center for Care and Wellbeing. We gratefully acknowledge the participating youths and professional representatives from the following 10 addiction treatment organizations for their valuable contributions to the study: Brijder Youth Addiction Treatment, Antes (Youz), Novadic-Kentron, Verslavingszorg Noord Nederland, IrisZorg, Arkin/Jellinek and Jellinek Utrecht, Tactus, Dimence, Mondriaan and De Hoop). Lastly, we kindly thank our research assistants Khedy Gorissen, Angela Rikumahu, Ilse Haarman, and Elsemieke Kunst.

\section{Authors' contributions}

$\mathrm{VH}, \mathrm{AG}$ and $\mathrm{PB}$ were primarily responsible for the design of the study and wrote the protocol with active input from DvdM, RS, AS, JdJ, FB and WV. CM and $\mathrm{VH}$ wrote the first draft of the manuscript with support of all co-authors. All authors contributed to the manuscript and approved its final version.

\section{Funding}

This study (60-63600-98-317) is funded by the Netherlands Organisation for Health Research and Development (ZonMW) and is supported by the Dutch Addiction Association. ZonMw and the Dutch Addiction Association had no further role in study design, nor in the collection, analysis and interpretation of the data or in the writing of the report.

\section{Availability of data and materials}

Not applicable, because our manuscript does not contain any data; it is a study protocol paper.

\section{Declarations}

\section{Ethics approval and consent to participate}

This study was approved by the Medical Ethical Board of the Leiden University Medical Center (NL65903.058.18; file number P18.175). Prior to study entry, all participants provide oral and written informed consent after receiving oral and written information on the objective and design of the study and the consequences of participation.

\section{Consent for publication}

Not applicable.

\section{Competing interests}

The authors declare that they have no competing interests.

\section{Author details}

1Parnassia Addiction Research Centre (PARC, Brijder Addiction Treatment) Zoutkeetsingel 40, 2512 HN The Hague, the Netherlands. ${ }^{2}$ Department of Child and Adolescent Psychiatry, LUMC Curium, Leiden University Medical Center, Leiden, the Netherlands. ${ }^{3}$ Department of Psychiatry, Academic Medical Centre, University of Amsterdam, Amsterdam, the Netherlands. ${ }^{4}$ Amsterdam Institute for Addiction Research, Arkin Mental Health Care, Amsterdam, the Netherlands. ${ }^{5}$ Department of Tranzo Scientific Center for Care and Wellbeing, Tilburg University, Tilburg, the Netherlands. ${ }^{6}$ Department of Psychiatry, Radboud University Medical Centre, Donders Institute for Brain, Cognition, and Behavior, Nijmegen, the Netherlands. ${ }^{7}$ Nijmegen Institute for Science Practitioners in Addiction (NISPA), Nijmegen, the Netherlands. ${ }^{8}$ Research Group Urban Vitality, Faculty of Health, Amsterdam University of Applied Science, Amsterdam, the Netherlands. ${ }^{9}$ Netherlands Network of Client Councils in Addiction Care 'Het Zwarte Gat', Hollands Kroon, The Netherlands. ${ }^{10}$ Department of Interdisciplinary Social Science, Utrecht University, Utrecht, the Netherlands.
Received: 6 July 2021 Accepted: 4 October 2021

Published online: 04 December 2021

\section{References}

1. De Graaf R. De psychische gezondheid van de Nederlandse bevolking. In: NEMESIS-2: Opzet en eerste resultaten. Utrecht: Trimbos-instituut; 2010.

2. Copeland WE, Shanahan L, Costello EJ, Angold A. Childhood and adolescent psychiatric disorders as predictors of young adult disorders. Arch Gen Psychiatry. 2009;66(7):764-72. https://doi.org/10.1001/archgenpsychiatry.2 009.85.

3. Coffey C, Carlin JB, Lynskey M, Li N, Patton GC. Adolescent precursors of cannabis dependence: findings from the victorian adolescent health cohort study. Brit J Psychiatry. 2003;182(4):330-6. https://doi.org/10.1192/bjp.182.4.330.

4. Chen CY, O'Brien MS, Anthony JC. Who becomes cannabis dependent soon after onset of use? Epidemiological evidence from the United States: 20002001. Drug Alc Dep. 2005;79(1):11-22. https://doi.org/10.1016/j.drugalcdep.2 004.11.014.

5. Swift W, Coffey C, Carlin JB, Degenhardt L, Patton GC. Adolescent cannabis users at 24 years: trajectories to regular weekly use and dependence in young adulthood. Addiction. 2008;103(8):1361-70. https://doi.org/10.1111/ j.1360-0443.2008.02246.x.

6. Prince van Leeuwen A, Creemers HE, Verhulst FC, WAM V, Ormel J, Van Oort $F$, et al. Legal substance use and the development of a DSM-IV cannabis use disorder during adolescence: the TRAILS study. Addiction. 2013;109: 303-11.

7. Lanza HI, Bello MS, Cho J, Barrington-Trimis JL, McConnell R, Braymiller JL, et al. Tabacco and cannabis poly-substance and poly-product use trajectories across adolescence and young adulthood. Prev Med. 2021;148: 106545. https://doi.org/10.1016/j.ypmed.2021.106545.

8. Hussong AM, Curran PJ, Moffitt TJ, Caspi A, Carrig MM. Substance abuse hinders desistance in young adults' antisocial behavior. Dev Psychopathol. 2004;16(4):1029-46. https://doi.org/10.1017/s095457940404012x

9. Copeland J, Swift W. Cannabis use disorder: epidemiology and management. Int RevPsychiat. 2009;21(2):96-103. https://doi.org/10.1080/ 09540260902782745

10. Moffitt TE. Adolescence-limited and life-course-persistent antisocial behavior: a developmental taxonomy. Psychol Rev. 1993;100(4):674-701. https://doi. org/10.1037/0033-295X.100.4.674

11. Moffitt TE. Life-course-persistent versus adolescence-limited antisocial behavior. In: Cichetti D, Cohen DJ, editors. Developmental psychopathology. Hoboken: John Wiley \& Sons, Inc; 2006. p. 570-98.

12. Flory K, Lynam D, Milich R, Leukefeld C, Clayton R. Early adolescent through young adult alcohol and marijuana use trajectories: early predictors, young adult outcomes, and predictive utility. Dev Psychopathol. 2004;16(1):193213. https://doi.org/10.1017/s0954579404044475.

13. Chassin L, Flora DB, King KM. Trajectories of alcohol and drug use and dependence from adolescence to adulthood: the effects of familial alcoholism and personality. J Abnormal Psychol. 2004;113(4):483-98. https:// doi.org/10.1037/0021-843X.113.4.483.

14. Nelson SE, Van Ryzin MJ, Dishion TJ. Alcohol, marijuana, and tobacco use trajectories from age 12 to 24 years: demographic correlates and young adult substance use problems. Dev Psychopathol. 2015;27(1):1-253-77-277. https://doi.org/10.1017/S0954579414000650.

15. Meier MH, Hall W, Caspi A, Belksy DW, Cerdá M, Harrington HLBS, et al. Which adolescents develop persistent substance dependence in adulthood? Using population-representative longitudinal data to inform universal risk assessment. Psychol Med. 2016;46(4):877-89. https://doi.org/10.1017/S00332 91715002482.

16. Lisdahl KM, Sher KJ, Conway KP, Gonzalez R, Feldstein Ewing SW, Nixon SJ, et al. Adolescent brain cognitive development (ABCD) study: overview of substance use assessment methods. Developm Cog Neurosci. 2018;32:8096. https://doi.org/10.1016/j.dcn.2018.02.007.

17. Wittchen HU, Fröhlich C, Behrendt S, Günther A, Rehm J, Zimmermann P, et al. Cannabis use and cannabis use disorders and their relationship to mental disorders: a 10-year prospective-longitudinal community study in adolescents. Drug Alc Dep. 2007;88S:S60-70. https://doi.org/10.1016/j.druga Icdep.2006.12.013.

18. Perkonigg A, Goodwin RD, Fiedler A, Behrendt S, Beesdo K, Lieb R, et al. The natural course of cannabis use, abuse and dependence during the first decades of life. Addiction. 2008:103(3):439-49. https://doi.org/10.1111/j.13 60-0443.2007.02064.x. 
19. Tanner-Smith EE, Wilson AJ, Lipsey MW. The comparative effectiveness of outpatient treatment for adolescent substance abuse: a meta-analysis. J Subs Abuse Treatm. 2013;44(2):145-58. https://doi.org/10.1016/j.jsat.2012.05. 006.

20. Godley SH, Dennis ML, Godley MD, Funk RR. Thirty-month relapse trajectory cluster groups among adolescents discharged from out-patient treatment. Addiction. 2004;99(Suppl 2):129-39. https://doi.org/10.1111/j.1360-0443.2004. 00860.x.

21. Chung T, Martin CS, Clark DB. Concurrent change in alcohol and drug problems among treated adolescents over three years. J Studies Alc Drugs. 2008;69(3):420-9. https://doi.org/10.15288/jsad.2008.69.420.

22. Chi FW, Sterling S, Campbell Cl, Weisner C. 12-step participation and outcomes over 7 years among adolescent substance use patients with and without psychiatric comorbidity. Subst Abus. 2013;34(1):33-42. https://doi. org/10.1080/08897077.2012.691780.

23. Wisselink DJ, Kuijpers WGT, Mol A. Kerncijfers Verslavingszorg 2015. LADIS, Landelijk Alcohol en Drugs Informatie Systeem, Houten; 2016.

24. Moska C, Spijkerman R, Blanken P, Hendriks V. Youth in transition questionnaire (YIT-Q). Hague: Parnassia Addiction Research Centre (PARC); 2018.

25. Lovibond SH, Lovibond PF. Manual for the depression anxiety stress scales. Sydney: The psychology foundation of Australia; 1995.

26. WHO. Disability Assessment Schedule 2.0: Handboek voor de classificatie van psychische stoornissen. DSM-5. Amsterdam: Uitgeverij Boom; 2014. p. 978-85.

27. de Beurs D, van Dyck R, Marquenie LA, Lange A, Blonk RW. De DASS: een vragenlijst voor het meten van depressie, angst en stress. Gedragstherapie. 2001;34:35-53.

28. Üstün TB, Chatterji S, Kostanjsek N, Rehm J, Kennedy C, Epping-Jordan J, et al. Developing the World Health Organization disability assessment schedule 2.0. Bull World Health Organ. 2010;88(11):815-23. https://doi.org/1 0.2471/BLT.09.067231.

29. Schippers GM, Broekman TG, Buchholz A, Koeter MWJ, Van den Brink W. Measurements in the addictions for triage and evaluation (MATE): an instrument based on the World Health Organization family of international classifications. Addiction. 2010;105(5):862-71. https://doi.org/10.1111/j.13600443.2009.02889.x

30. American Psychiatric Association. Diagnostic and statistical manual of mental disorders. 5th ed. Washington DC; American Psychiatric Association: 2013.

31. Ising HK, Veling W, Loewy RL, Rietveld MW, Rietdijk J, Dragt S, et al. The validity of the 16-item version of the prodromal questionnaire (PQ-16) to screen for ultra high risk of developing psychosis in the general helpseeking population. Schizophr Bull. 2012;38(6):1288-96. https://doi.org/10.1 093/schbul/sbs068

32. Conrod PJ, Castellanos-Ryan N, Mackie C. Long-term effects of a personalitytargeted intervention to reduce alcohol use in adolescents. J Consult Clin Psychol. 2011;79(3):296-306. https://doi.org/10.1037/a0022997.

33. Nijman $H$, Kaal $H$, Scheppingen $V L$, Moonen $X$. Development and testing of a screener for intelligence and learning disabilities (SCIL). J Res Intellect Disabil. 2016;31(1):59-67. https://doi.org/10.1111/jar.12310.

34. Savill M, D'Ambrosio J, Cannon TD, Loewy RL. Psychosis-risk screening in different populations using the prodromal questionnaire - a systematic review. Early Interv Psychiatry. 2018;12(1):3-4. https://doi.org/10.1111/ eip.12446.

35. Woicik PA, Stewart SH, Pihl RO, Conrod PJ. The substance use risk profile scale: a scale measuring traits linked to reinforcement-specific substance use profiles. Addict Behav. 2009;34(12):1042-55. https://doi.org/10.1016/j.a ddbeh.2009.07.001.

36. Lecrubier $Y$, Weiller E, Heguerta $T$, Amorim $P$, Bonora LI, Lépine JP, et al. MINI International Neuropsychiatric Interview. Maastricht: Nederlandse Versie 5.0.0. DSM-IV: Universiteit van Maastricht; 1999.

37. Schuckit MA, Clarke DF, Mendoza LA. Schoen L (2020). The search for contributors to low rates of recognition of paternal alcohol use disorders in offspring from the San Diego prospective study. Alcohol Clin Exp Res. 2020; 44(8):1551-60. https://doi.org/10.1111/acer.14401.

38. Dunne MP, Zolotor AJ, Runyan DK, Andreva-Miller I, Choo WY, Dunne SK, et al. ISPCAN child abuse screening tools retrospective version (ICAST-R): Delphi study and field testing in seven countries. Child Abuse Negl. 2009:33:826-32.

39. Teruya C, Hser Y. Turning points in the life course: current findings and future directions in drug use research. Curr Drug Abuse Rev. 2010;3(3):18995. https://doi.org/10.2174/1874473711003030189.
40. Neale J, Vitoratou S, Finch E, Lennon P, Mitcheson L, Panebianco D, et al. Development and validation of 'SURE': a patient reported outcome measure (PROM) for recovery from drug and alcohol dependence. Drug Alc Dep. 2016:165:159-67. https://doi.org/10.1016/j.drugalcdep.2016.06.006.

41. Marsden J, Farrell M, Bradbury C, Dale-Perera A, Eastwood B, Roxburgh M, et al. Development of the treatment outcomes profile. Addiction. 2008; 103(9):1450-60. https://doi.org/10.1111/j.1360-0443.2008.02284.x.

42. Black N, Chung S, Fialho LS, Aramrattana A, Assanangkornchai S, Blaszynski A, Bowden-Jones H, Van den Brink W, Brown A, et al. An international, multidisiplinary consensus standard set of outcome measures for substance use and addictive behaviour disorders. 2021. https://connect.ichom.org/ standard-sets/disorders-related-to-substance-abuse-or-addictive-behaviours/

43. Pooseh S, Bernhardt N, Guevara A, Huys QJM, Smolka MN. Value-based decision-making battery: a Bayesian adaptive approacht to assess impulsive and risky behavior. Behav Res. 2018;50(1):236-49. https://doi.org/10.3758/ s13428-017-0866-X.

44. Petrides M, Milner B. Deficits on subject-ordered tasks after frontal- and temporal-lobe lesions in man. Neuropsychologia. 1982;20(3):249-62. https:// doi.org/10.1016/0028-3932(82)90100-2.

45. Paulus MP, Rogalsky C, Simmons A, Feinstein JS, Stein MB. Increased activation in the right insula during risk-taking decision making is related to harm avoidance and neuroticism. Neuroimage. 2003;19(4):1439-48. https:// doi.org/10.1016/S1053-8119(03)00251-9.

46. Stevens L, Verdejo-Garcia A, Goudriaan AE, Roeyers H, Dom G, Vanderplasschen W. Impulsivity as a vulnerability factor for poor addiction treatment outcomes: a review of neurocognitive findings among individuals with substance use disorder. J Subst Abus Treat. 2014;47(1):58-72. https:// doi.org/10.1016/j.jsat.2014.01.008.

47. Anokhin AP, Golosheykin S, Mulligan RC. Long-term test-retest reliability reward discounting in adolescent. Behaviorual Process. 2015;11:55-9. https://doi.org/10.1016/j.beproc.2014.11.008.

48. Vives AH, De Angel V, Papadopoulos A, Strawbridge R, Wise T, Young AH, et al. The relationship between cortisol, stress and psychiatric illness: new insights using hair analysis. J Psychiat Res. 2015;70:38-49. https://doi.org/1 0.1016/j.jpsychires.2015.08.007.

49. Staufenbiel SM, Penninx BWJH, Spijker AT, Elzinga BM, Van Rossum EFC. Hair cortisol, stress exposure, and mental health in humans: a systematic review. Psychoneuroendocrinology. 2013;38(8):1220-35. https://doi.org/10.1016/j. psyneuen.2012.11.015.

50. Deuter CE, Duesenberg M, Hellmann-Regen J, Metz S, Roepke S, Wolf OT, et al. Psychosocial stress increases testosterone in patients with borderline personality disorder, post-traumatic stress disorder and healthy participants. Borderline Personal Disord Emot Dysregul. 2021;8(1):3. https://doi.org/10.11 86/s40479-021-00145-X.

51. Petry NM, Alessi SM, Marx J, Austin M, Tardif M. Vouchers versus prizes: contingency management treatment of substance abusers in community settings. J Consult Clin Psychol. 2005;73(6):1005-14. https://doi.org/10.1037/ 0022-006X.73.6.1005

52. Anderson KG, Ramo DE, Cummins KM, Brown SA. Alcohol and drug involvement after adolescent treatment and functioning during emerging adulthood. Drug Alc Dep. 2010;107(2-3):71-181. https://doi.org/10.1016/j. drugalcdep.2009.10.005.

53. Naing L, Winn T, Rusli BN. Practical issues in calculating the sample size for prevalence studies. Arch Orofacial Sci. 2006;1:9-14.

54. National Statistical Service. http://www.nss.gov.au. Accessed 5 Apr 2017.

55. Peduzzi P, Concato J, Kemper E, Holford TR, Feinstein AR. A simulation study of the number of events per variable in logistic regression analysis. J Clin Epidem. 1996;49(12):1373-9. https://doi.org/10.1016/S0895-4356(96)00236-3.

56. Vittinghoff $E, M c C u l l o c h ~ C E$. Relaxing the rule of ten events per variable in logistic and cox regression. Am J Epidem. 2006;165(6):710-8. https://doi. org/10.1093/aje/kwk052.

57. Steyerberg EW, Eijkemans MJC, Harrell FE, Habbema JDF. Prognostic modelling with logistic regression analysis: a comparison of selection and estimation methods in small data sets. Stat Med. 2000;19(8):1059-79. https://doi.org/10.1 002/(SICI)1097-0258(20000430)19:8<1059::AID-SIM412>3.0.CO;2-0.

58. Ormel J, Oldehinkel AJ, Sijtsema J, Van Oort F, Raven DMA, Veenstra R, et al. The tracking adolescents' individual lives survey (TRAILS): design, current status, and selected findings. J Americ Acad Child Adolesc Psychiat. 2012; 51(10):1020-36. https://doi.org/10.1016/j.jaac.2012.08.004.

59. Hosmer DW, Lemeshow S. Applied logistic regression. New York: John Wiley \& Sons; 2000. https://doi.org/10.1002/0471722146. 
60. Muthén B, Muthén LK. Integrating person-centered and variable-centered analyses: growth mixture modeling with latent trajectory classes. Alcohol Clin Exp Res. 2000;24(6):882-91. https://doi.org/10.1111/j.1530-0277.2000. tb02070.x.

61. Secades-Villa R, Fernández-Hermida JR. The validity of self-reports in a follow-up study with drug addicts. Addict Behav. 2003;28(6):1175-82. https://doi.org/10.1016/S0306-4603(02)00219-8.

62. Jackson CT, Covell NH, Frisman LK, Essock SM. Validity of self-reported drug use among people with co-occurring mental health and substance use disorders. J Dual Diagnosis. 2005;1(1):49-63. https://doi.org/10.1300/J374v01n01_05.

\section{Publisher's Note}

Springer Nature remains neutral with regard to jurisdictional claims in published maps and institutional affiliations.

Ready to submit your research? Choose BMC and benefit from:

- fast, convenient online submission

- thorough peer review by experienced researchers in your field

- rapid publication on acceptance

- support for research data, including large and complex data types

- gold Open Access which fosters wider collaboration and increased citations

- maximum visibility for your research: over $100 \mathrm{M}$ website views per year

At $\mathrm{BMC}$, research is always in progress.

Learn more biomedcentral.com/submissions 